Kerner, C., Haerens, L., and Kirk, D.

\title{
Body dissatisfaction, perceptions of competence and lesson content in physical education
}

\begin{abstract}
BACKGROUND Significant proportions of young people experience body dissatisfaction, which has implications for psychological and physical well-being. Little is known about how factors within physical education support or hinder the development of body satisfaction. Lesson content and perceived competence may be important variables for the experience of body dissatisfaction, yet these have been underexplored in physical education. The aim of this cross sectional study is to identify the relationships between body dissatisfaction and perceptions of competence, and to explore whether body dissatisfaction depends on lesson content.
\end{abstract}

METHODS A paper and pencil questionnaire was completed by 446 (210 males, 236 females) 13-14-year-old pupils from 37 physical education classes. The questionnaire assessed body dissatisfaction and perceived competence in physical education. Lesson content was also recorded. Twenty-nine of the classes were engaged in team activities, for example, ball games. Eight classes were engaged in individual activities, for example, fitness.

RESULTS Multilevel analysis identified a significant negative association between body dissatisfaction and perceptions of competence in physical education. Lesson content did not significantly predict variations in body dissatisfaction scores.

CONCLUSIONS Findings suggest that teachers should focus on enhancing pupils' perceptions of competence in physical education in order to support the development of body satisfaction. 
Kerner, C., Haerens, L., and Kirk, D.

KEY WORDS: Body dissatisfaction, perceptions of competence, physical education, adolescents, lesson content.

Approximately $70 \%$ of adolescent girls and $45 \%$ of adolescent boys' experience body dissatisfaction. ${ }^{1}$ Body dissatisfaction in adolescence has been linked to a number of health outcomes such as depression ${ }^{2}$ and physical inactivity. ${ }^{3}$ Due to the longitudinal negative associations between body dissatisfaction in adolescents and future health related behaviours ${ }^{4}$ early intervention to reduce body dissatisfaction is appropriate. It has been argued that physical education has the potential to act as an appropriate body image intervention site $^{5}$. Yet, little is known about the specific practical strategies that could be implemented within physical education in order to reduce body dissatisfaction. ${ }^{6}$ In order to develop effective physical education based body image interventions and to reduce body focused anxiety research is needed to understand the links between contextual factors within physical education and body dissatisfaction.

Body image intervention work in physical education is limited but those programmes that exist have focused on implementing activities that enhance perceptions of physical competence. ${ }^{7}$ Perceptions of competence can be defined as an individual's belief about their ability within an achievement domain (such as physical education). ${ }^{8}$ Perceived competence is important for engagement and participation in youth physical activity and physical education, ${ }^{9,10}$ however, empirical links with body dissatisfaction in physical education are less well established. Generally those people with higher levels of perceived physical competence also experience less body dissatisfaction. For example, in the general physical activity domain, positive associations have been identified between perceived physical appearance and perceived athletic competence in adolescent girls. ${ }^{11}$ Furthermore, a positive association has been established between perceived athletic competence and body esteem in high school football players. ${ }^{12}$ Similarly, increased physical competence in a competitive 
Kerner, C., Haerens, L., and Kirk, D.

school sport context has been associated with increased body satisfaction in 17-25 year olds. ${ }^{13}$ The extent to which perceived physical competence in physical education is associated with body dissatisfaction is, however, currently underexplored. If the negative association between perceived physical competence and body dissatisfaction is also evident within the physical education context, this can begin to inform an evidence base on how to reduce body dissatisfaction in physical education, for example through the implementation of competence supportive teaching behaviours. ${ }^{14}$ We hypothesize that pupils who experience higher greater levels of body dissatisfaction will be less likely to perceive themselves as physically competent in physical education.

Sex differences between body dissatisfaction and perceived competence in physical education are well established within the literature. Boys consistently report higher levels of perceived competence compared to girls ${ }^{15}$ and lower levels of body dissatisfaction. ${ }^{1}$ In relation to body dissatisfaction, adolescence is a time of physical change associated with an increased focus and evaluation of the body for both boys and girls. ${ }^{16}$ For girls, puberty tends to lead to increases in body fat and thus a shift away from the slim ideal female body. ${ }^{17}$ Thus, adolescent girls' body dissatisfaction is generally associated with a desire to be thinner. ${ }^{18}$ Estimates of the prevalence of body dissatisfaction vary across studies. For example, in a sample of adolescent girls aged between 11 and 15, body dissatisfaction was reported at $24 \% .{ }^{19}$ However, a review paper reported an $80 \%$ prevalence of dissatisfaction in similar populations. ${ }^{20}$ With this variation in mind, it is estimated that between $50 \%$ and $80 \%$ of adolescent girls have a desire to be thinner. ${ }^{21}$ Most evidence would suggest that the prevalence of body dissatisfaction is less in males compared to females. ${ }^{1,}{ }^{20}$ However, some argue that it is the processes that underlie body dissatisfaction that differ and not the prevalence. For example, male body dissatisfaction can also be characterised by concerns over aspects of the body which emphasis masculinity, such as the shoulders, chest and 
Kerner, C., Haerens, L., and Kirk, D.

abdomen. ${ }^{22}$ Approximately a third of adolescent boys have a desire to be more muscular, while another third of boys have a desire to be thinner. ${ }^{23,24}$ Although most of the literature would suggest higher dissatisfaction in girls, if these processes are combined, the resulting dissatisfaction could be of relatively equal prevalence in boys and girls. ${ }^{25}$ We hypothesise that levels of body dissatisfaction would be approximately equal in males and females, but the direction of dissatisfaction (eg a desire for a larger or a smaller body) would differ between the sexes, Furthermore, we hypothesize that boys will perceive themselves as physically more competent.

Another factor that may link to body dissatisfaction is physical education lesson content. Lesson contents in which pupils feel their bodies are exposed to the social scrutiny of others may be important for the experience of body dissatisfaction. ${ }^{6}$ This issue has been explored through a comparison of swimming and aerobics lessons with adolescent girls. ${ }^{7}$ Adolescent girls experienced increases in body dissatisfaction when in swimming lessons compared to aerobics after a six-week programme. ${ }^{7}$ Outside of physical education, participation in individual sports is associated with higher body dissatisfaction than team sports in 12-year-old boys. ${ }^{26}$ It is argued that team activities may protect against social evaluations as the focus is on the group and not the individual, whereas individual activities allow for more one-on-one comparison. ${ }^{26}$ However, it is unknown whether these findings apply to participation in team and individual lesson contents in physical education. Given the literature outside of physical education, it is hypothesised that pupils participating in individual activities in physical education will be more likely to report body dissatisfaction than pupils engaging in team-based activities.

Addressing these gaps within the literature, the study firstly aimed to explore sex differences in body dissatisfaction and perceptions of competence between boys and girls. Secondly, the study aims to explore the relationships between body dissatisfaction and 
Kerner, C., Haerens, L., and Kirk, D.

perceptions of competence. The study will also explore differences in body dissatisfaction across lesson content (team vs individual activities) in physical education.

\section{METHOD}

\section{Participants and Procedures}

Schools in the South East of the United Kingdom were invited to participate in the current study through email. Four schools responded positively to the call for participation. All pupils and parents/carers within each year 9 physical education class in these schools was provided with an information sheet that outlined the requirements of the study and was invited to participate through passive consent procedures. Research ethics was granted from the participating research institution. Participants were 446 (210 male, 236 female) year nine pupils (aged 13-14 years old) from 37 physical education classes. Pupils completed a paper and pencil questionnaire package during one physical education lesson. The questionnaire took approximately 20 minutes for pupils to complete. Pupils were instructed to respond to all items on the questionnaires. Pupils were supervised by the researcher and the class teacher throughout the process, who were available to clarify instructions and provide support for comprehension.

\section{Instrumentation}

Perceptions of competence. The perceived competence subscale of the Intrinsic Motivation Inventory ${ }^{27}$ was used to assess adolescents' perceptions of competence within Physical Education. Participants were asked to respond to "number of" items (eg I am satisfied with my performance on this task) on a 7-point Likert scale, ranging from 1 (not true for me) to 7 (very true for me). An alpha coefficient of 0.83 was identified, thus, based upon criterion of $.70^{28}$ the scale was deemed to have acceptable internal consistency. 
Kerner, C., Haerens, L., and Kirk, D.

Body dissatisfaction. The BMI-based Silhouette Matching Test was used to assess body dissatisfaction. ${ }^{29,30}$ The measure is a figural rating scale derived from anthropometric data of $9^{\text {th }}-12^{\text {th }}$ grade Canadian male and female adolescents. ${ }^{29}$ Participants were presented with a sex specific scale consisting of four silhouette drawings with a 27 interval scale. Each box along the scale coincides with a BMI score ranging from 14 to 40 . The four silhouette images provide visual reference points and represent BMI values of 18, 24, 30 and 36. Participants were asked to place an ' $\mathrm{X}$ ' in one of the 27 boxes on the scale which they think best reflects their current appearance and an ' $\mathrm{X}$ ' in the box that represents their ideal appearance. Body dissatisfaction was determined by a discrepancy between the perceived current and ideal physique, with a higher larger value representing more dissatisfaction.

Lesson Content. The lesson content of each class was recorded by the researcher at the time when the pupils completed the questionnaires. Twenty-nine of the classes were engaged in team activities (eg ball games), compared to eight classes engaged in individual activities (eg fitness and artistic activities).

\section{Data Analysis}

Given the structure of the data with a range of 446 pupils nested within 37 physical education classes, and the adequate sample size for conducting multilevel analysis, multilevel regression analysis was employed using MLWiN version 2.26. The data was treated as a two level model consisting of pupils at the first level and classes at the second level. Body dissatisfaction was entered into the model at the dependent variable. A two level model yielded a significantly better fit that a one level model, $\chi^{2}(1)=206.15, p<.001$, therefore an intercept only model was used to evaluate how much of the variance in body dissatisfaction scores could be attributed to both levels (Table 1: null model). Each predictor was entered individually (model 1 and 2) and then simultaneously (model 3) into the null model. 
Kerner, C., Haerens, L., and Kirk, D.

\section{RESULTS}

Pupils reported an average body dissatisfaction score of $3.82( \pm 3.58)$, suggesting that they would prefer a physique that is different by a BMI of 3.82. There were no significant differences in the body dissatisfaction scores between boys $(3.59 \pm 3.36)$ and girls $(3.58 \pm$ $3.75), \chi^{2}(1)=1.00, p>.05$. Pupils participating in team activities, reported a mean body dissatisfaction score of $4.07( \pm 3.66)$ compared to a mean dissatisfaction score of $3.24( \pm$ 3.29) in individual activities. These differences were non-significant.

Of all pupils, $18.4 \%$ were satisfied with their current body size, with $19.5 \%$ of boys and $17.4 \%$ of girls reporting no discrepancy between their perceived current BMI and ideal BMI. Overall, 25.1\% of all pupils reported an ideal physique that was bigger than their current physique. For boys $35.7 \%$ desired a larger body size, compared to $15.7 \%$ of girls. Overall, $56.5 \%$ of pupils reported an ideal physique that was smaller than their current physique. For boys, $44.8 \%$ desired a smaller body size, compared to $66.9 \%$ of girls.

Pupils reported an average perception of competence score of $4.71( \pm 1.19)$ on a Likert scale ranging from 1-7, suggesting that most pupils agreed just above moderately that they perceived themselves as physically competent in physical education. There was a significant difference in the perceptions of competence scores between boys $(4.79 \pm 1.11)$ and girls $(4.32$ $\pm 1.20), \chi^{2}(1)=8.15, \mathrm{p}=.04$

To examine the relationships between body dissatisfaction, perceptions of competence and lesson content a two level model was estimated. Ninety-three percent of the variance in body dissatisfaction scores was situated at the pupil level, level, $\chi^{2}(1)=206.15, \mathrm{p}<.001$, with the remaining $7 \%$ of the variance at the between class level, $\chi^{2}(1)=1.62, p=.20$ (null model). In order to see if lesson content or perceptions of competence significantly predicted the variance in body dissatisfaction scores, all variables were entered separately (table 1). 
Kerner, C., Haerens, L., and Kirk, D.

Pupils who reported higher body dissatisfaction scores also reported low perception of competence scores, $\beta=-0.80, \mathrm{SE}=0.14, \chi^{2}(1)=33.07, \mathrm{p}<.001(\operatorname{model} 1)$. There was no significant difference in body dissatisfaction scores between team and individual activities, $(\beta$ $\left.=-0.80, \mathrm{SE}=0.37, \chi^{2}(1)=2.40, \mathrm{p}=.12\right)(\operatorname{model} 2)$.

\section{DISCUSSION}

Given the impact that adolescent body dissatisfaction has on a range of health outcomes $^{2,3}$ and advocacy for health and physical education teachers to play a role in developing and designing programmes to support the development of a positive body image ${ }^{31}$ the purpose of this paper is to identify the relationships between body dissatisfaction, perceptions of competence and lesson content in physical education, and to explore any sex differences in these relationships.

The study found that body dissatisfaction was not significantly different in boys and girls. These findings can be contrasted with other studies which suggest levels of dissatisfaction are higher in girls compared to boys. ${ }^{1}$ However, female body dissatisfaction in the current study was characterised by a desire for a smaller BMI (66.9\%), as has been evidenced elsewhere, ${ }^{18}$ and is aligned with the socio-cultural messages of slenderness associated with female physical attractiveness. For boys, body dissatisfaction was more equally combined across a desire for a smaller body size (44.8\%) and a desire for a larger body size $(35.7 \%)$. It is suggested that if these two processes of body dissatisfaction are combined then the amount of body dissatisfaction in adolescent boys and girls is similar. ${ }^{25}$ It could be argued that boys whose body dissatisfaction was characterised by a desire for a larger BMI, were striving for a more muscular physique in line with the socio-cultural messages associated with an ideal male physique. These interpretations of our data support previous arguments that male body dissatisfaction is a dual pathway of concerns about 
Kerner, C., Haerens, L., and Kirk, D.

muscularity and concerns about weight. ${ }^{32}$ These findings provide support for the provision of body image education in schools for both adolescent boys and girls.

Furthermore, the study reported that perceptions of competence in physical education is more important than lesson content in predicting variations in body satisfaction. Those that perceived themselves as more physically competent in physical education were more likely to report lower body dissatisfaction scores and vice-versa. These findings can be compared with the outcomes identified in the general physical activity domain. ${ }^{11}$ and competitive sport contexts $^{12,13}$ that show a negative relationship between perceived physical competence and body dissatisfaction. As the current study is cross-sectional, the implications of the findings can be discussed in two ways. First, it might be important for physical education teachers to take into account that those adolescents who are highly dissatisfied with their body will also be more likely to feel less competent during physical education. On the other hand, if physical education teachers manage to create lessons in which adolescents feel competent, for instance, by providing more positive feedback and clear guidelines, ${ }^{14,33}$ this could diminish adolescents' body dissatisfaction. Additionally, consideration could be given to the implementation of an Activist Approach in physical education that supports pupil engagement in physical education lessons through student centred pedagogy and pedagogies of embodiment. ${ }^{34}$

Based upon previous evidence in a general sports context ${ }^{26}$ it was anticipated that body dissatisfaction would be higher in individual activities compared to team based activities, however, the current study identified no significant differences between the two lesson contents. It has been argued that individual activities may promote social comparison and thus increase body dissatisfaction. ${ }^{26}$ Previous studies have focused on prolonged engagement in a competitive sport context. It may be in contrast that the short duration of a physical education unit prevents pupils from internalising the heightened social comparisons 
Kerner, C., Haerens, L., and Kirk, D.

that may be made in an individual activity context. Furthermore, the design of the current study may have impacted the findings. For example, there was an unequal distribution of classes across the two categories of individual and team based activities, which reflects the games-dominated curriculum within physical education programmes in the UK. Future research should consider a more balanced design with individual and team sports more equally distributed.

\section{Limitations}

There are several limitations in this study. Firstly, the cross-sectional nature of the study design means that causal inference cannot be established. Furthermore, the design of the current study led to an unequal distribution of lesson contents across team and individual activities. Teachers were not asked to change their lesson contents and measurements were taken during lessons that would normally have taken place. The development of an intervention design to establish causality should be applied in future research. For example, the cross over intervention design of previous studies, ${ }^{7}$ in which comparisons were made between swimming and aerobic lessons, could be applied. This could include the manipulation of lesson contents or teacher behaviours in order to develop perceived competence. $^{33}$

In addition, other contextual factors between the physical education classes could have impacted the findings. For example, teacher and peer influence are important factors to consider for body image outcomes in physical education ${ }^{35}$ and were not controlled for within the current study. Lesson content has been considered elsewhere to be an important factor to consider in physical education-based body image interventions ${ }^{7}$ and should be developed in future research through more robust research designs. 
Kerner, C., Haerens, L., and Kirk, D.

Additionally, although the measurement tool used allows for the identification of body dissatisfaction associated with a desire for a smaller or larger body, it does not specifically indicate differences in body dissatisfaction as a result of muscularity. Future research that explores gender differences should consider assessment tools that consider dissatisfaction associated with both a desire to be thinner and dissatisfaction associated with increased muscularity.

\section{Conclusions}

The current study reinforces the trends of previous research in which it was found that a significant proportion of young people are dissatisfied with their body size. These findings highlight the need for action to tackle issues of body dissatisfaction and support the development of body satisfaction in adolescents. Physical education has a key role to play in supporting the development of body satisfaction in children and adolescents ${ }^{6,31}$ given it is the only school based subject in which the moving body is the main medium of learning. The findings from this research can be used to inform future physical education programmes that support the development of body satisfaction. Although body dissatisfaction was not experienced differently across team and individual activities in physical education, future intervention-based designs should be considered to explore this issue further. Moreover, the significant relationships between perceptions of competence and body dissatisfaction suggest that developing perceived physical competence in physical education may be an appropriate strategy for body image programmes. This focus on developing an awareness of functional aspects of the body, or in other words, focusing on what the body can do as oppose to what the body looks like, through physical education may divert attention away from wider sociocultural messages that focus on valuing aesthetic qualities of the body.

\section{IMPLICATIONS FOR SCHOOL HEALTH}


Kerner, C., Haerens, L., and Kirk, D.

Previous research has argued for the inclusion of school-based interventions to promote the development of a positive body image. ${ }^{36}$ Although there is a tendency for body image programmes to focus on decreasing body dissatisfaction in females, our findings suggest that initiatives should consider the equal distribution of body dissatisfaction that was identified in the current study and thus develop programmes to support both boys and girls. However, when teachers are implementing school-based body image programmes consideration could be given to the differing socio-cultural definitions of the ideal physique and the impact that this has on the body dissatisfaction process across sexes. Specifically, in physical education this may involve the acknowledgement of how current gendered practices may support or challenge the body image socialisation process that occurs outside of the lesson. For example, participation in certain physical activities may reinforce gendered body norms and perpetuate wider socio-cultural messages of what a male and a female body should look like. Physical educators should challenge these gendered practices, ensuring as a starting point that all pupils have access to a full range of sporting activities rather than only those considered traditionally to be gender-appropriate.

Alongside offering a range of activities to boys and girls, there are a number of other practical strategies that physical education teachers can use to support the development of body satisfaction. The significant association that was identified between perceptions of competence and body dissatisfaction within this study can inform these practical strategies. This could be achieved through the implementation of activities and teaching behaviours within physical education that support the development of competence in adolescent boys and girls. Based upon the principals of need supportive teaching behaviours outlined by selfdetermination theory there are certain strategies that physical education teachers can implement. ${ }^{14}$ For example, to develop competence in physical education, teachers should provide pupils with clear guidelines on how to complete an activity, alongside a clearly 
Kerner, C., Haerens, L., and Kirk, D.

defined rationale outlining the purpose of the activity. Moreover, teachers should ensure that they outline expectations and provide feedback on performance within lessons. ${ }^{33}$

In terms of the practical implications at a broader level, schools should increase their awareness of the potential role that physical education can play in classroom-based body image programmes. Practically schools should provide increased opportunities for participation in physical activity and specifically physical education. This would allow young people to experience physical movement through practices that focus on the functional capabilities of their bodies provides opportunities to value their bodies as more than an aesthetic object.

\section{Human Subjects Approval Statement}

The institutional review board at the University of Bedfordshire at which this research was conducted approved the study, with the following approval code 2011PESP018.

\section{REFRERENCES}

1. Smolak L. Appearance in childhood and adolescence. In Rumsey N, Harcourt D, eds. Oxford Handbook of the Psychology of Appearance. London: Oxford University Press; 2012:123-141.

2. Brechan I, Kvalem IL. Relationship between body dissatisfaction and disordered eating: mediating role of self-esteem and depression. Eat Behav. 2015;17:49-58.

3. Kantanista A, Osinski W, Borowiec J, Tomczak M, Krol-Zielinska M. Body image, BMI and physical activity in girls and boys aged 14-16 years. Body Image. 2015;15:40-43.

4. Neumark-Sztainer D, Paxton SJ, Hannan PJ, Haines J, Story M. Does body satisfaction matter? Five year longitudinal associations between body satisfaction and health behaviours in adolescent males and females. $J$ Adolesc Health. 2006;39(2):244-251. 
Kerner, C., Haerens, L., and Kirk, D.

5. Duncan MJ, Al-Nakeeb Y, Nevill A, Jones MV. Body image and physical activity in British secondary school children. Eur Phys Educ Rev. 2004;10(3):243-260.

6. Kerner C, Haerens L, Kirk D. Body image in physical education: current knowledge and future directions. Eur Phy Educ Rev.2017; iFirst. DOI: 10.1177/1356336X17692508

7. Burgess GR, Grogan S, Burwitz L. Effect of a 6-week aerobic dance intervention on body image and physical self-perceptions in adolescent girls. Body Image. 2006;3(1):57-66.

8. Harter S. The perceived competence scale for children. Child Dev. 1982;53(1):87-97. 9. Fairclough S. Physical activity, perceived competence and enjoyment during high school physical education. Eur Phys Educ Rev. 2003;8(1):5-18.

10. De Meester A, Maes J, Stodden D. Identifying profiles of actual and perceived motor competence among adolescents: associations with motivation, physical activity, and sport participation. J Sport Sci.2016;34(21):2027-2037.

11. Craft LL, Pfeiffer KA, Pivarnik JM. Predictors of physical competence in adolescent girls. J Youth Adolesc. 2003;32(6):431-438.

12. Mackinnon DP, Goldberg L, Cheong J, Elliot D, Clarke G, Moe E. Male body esteem and physical measurements: Do leaner, or stronger, high school football players have a more positive body image? J Sport ExercPsychol. 2003;25(3):307-322.

13. Greenleaf C, Boyer EM, Petrie TA. High school sport participation and subsequent psychological well-being and physical activity: The mediating influences of body image, physical competence and instrumentality. Sex Roles. 2009;61(9-10):714-726.

14. Haerens L, Aelterman N, Van den Berghe L, De Meyer J, Soenens B, Vansteenkiste M. Observing physical education teachers' need-supportive interactions in classroom settings. $J$ Sport Exerc Psychol. 2013;35(1):3-17.

15. Lyu M, Gill DL. Perceived competence and body image as predictors of perceived peer acceptance in adolescents. Asian J Soc Psychol. 2012;15(2):37-48. 
Kerner, C., Haerens, L., and Kirk, D.

16. Abbott BD, Barber BL. Embodied image: Gender differences in functional and aesthetic body image among adolescents. Body Image. 2010;7(1):22-31.

17. McCabe MP, Ricciardelli LA. Sociocultural influences on body image and body changes among adolescent boys and girls. J Soc Psychol. 2006;143(1):5-26.

18. Tiggemann M. Body image across the adult lifespan: Stability and change. Body Image. 2004;1(1):29-41.

19. Stice E, Whitenton K. Risk factors for body dissatisfaction in adolescent girls: A longitudinal investigation. Dev Psychol. 2002;38(5):669-678.

20. Cohane GH, Pope HG. Body Image in boys: a review of literature. Int J Eat Disord. $2001 ; 29(4): 373-379$.

21. Levine MP, Smolak L. Body image development in adolescence. In Cash TF, Pruzinsky T, eds. Body image: A handbook of theory research and clinical practice. New York; Guilford Press;2002:74-82.

22. Ricciardelli LA, McCabe MP, Ridge D. The construction of the adolescent male body through sport. J Health Psychol. 2006;11:577-587.

23. Furnham A, Calman A. Eating disturbance, self-esteem, reasons for exercising and body weight dissatisfaction in adolescent males. Eur Eat Disord Rev. 1998;6(1):58-72.

24. Ricciardelli LA, McCabe MP. A longitudinal analysis of the role of biopsychosocial factors in predicting body change strategies among adolescent boys. Sex Roles. 2003;48:349359.

25. McCabe MP, Ricciardelli LA. Weight and shape concerns of boys and men. In Thompson JK, eds. Handbook of Eating Disorders and Obesity. New York: Wiley; 2004: 606-634.

26. Morano M, Colella D, Capranica L. Body Image, Perceived and Actual Physical Abilities in Normal-Weight and Overweight Boys Involved in Individual and Team Sports. $J$ Sports Sci. 2011;29(4):355-362 
Kerner, C., Haerens, L., and Kirk, D.

27. McAuley E, Duncan T, Tammen V. Psychometric properties of the intrinsic motivation inventory in a competitive sport setting: A confirmatory factor analysis. Res Q Exerc Sport. $1989 ; 60(1): 48-58$.

28. Nunnally JC. Psychometric Theory, $2^{\text {nd }}$ ed. New York: McGraw-Hill.

29. Peterson M, Ellenberg D, Crossan S. Body-image perceptions: reliability of a BMI-based Silhouette Matching Test. Am J Health Behav. 2003;27(4):355-363.

30. Peterson M, Orsega-Smith E, Tholstrup L. Validity of the body mass index silhouette matching test. Am J Health Behav. 2004;28(5):437-434.

31. Evans RR, Roy J, Geiger BF, Werner KA, Burnett D. Ecological strategies to promote healthy body image among children. J Sch Health. 2008;78(7):359-367.

32. Jones DC, Crawford JK. Adolescent boys and body image: Weight and muscularity concerns as dual pathways to body dissatisfaction. J Youth Adolesc. 2005;34(6):629-636. 32. Aelterman N, Vansteenkiste M, Van den Berghe L, et al. Fostering a need-supportive teaching style: intervention effects on physical education teachers' beliefs and teaching behaviors. J Sport Exerc Psyhol. 2014;36(6):595-609.

34. Oliver K, Kirk D. Transformative pedagogies for challenging body culture in physical education. In Ennis CD, eds. Routledge Handbook of Physical Education Pedagogies. Abington: Routledge International Handbooks; 2016:307-318.

35. Carmona J, Tornero-Quiñones I, Sierra-Robles-A. Body image avoidance behaviors in adolescence: A multilevel analysis of contextual effects associated with the physical education class. Psychol Sport Exerc. 2015;16(3):70-78

36. Choi JS, Kim JS. Mediating effect of body image distortion on weight loss effects in normal-weight and underweight Korean adolescent girls. J Sch Health. 2017:87(3):217-224. 
Kerner, C., Haerens, L., and Kirk, D.

Table 1-Multilevel Analysis of Relationships Between Body Dissatisfaction and Perceptions of Competence and Differences in Body Dissatisfaction Across Individual and Team Activities.

\begin{tabular}{|c|c|c|c|c|}
\hline Parameter & Model 0 & Model 1 & Model 2 & Model 3 \\
\hline Fixed Part & $\beta$ (S.E.) & $\beta$ (S.E.) & $\beta$ (S.E.) & $\beta$ (S.E.) \\
\hline Intercept & $3.82(0.23)$ & $3.86(0.19)$ & $4.07(0.26$ & $3.99(0.22)$ \\
\hline Perceptions of competence & & $-0.80(0.14)^{* * *}$ & & $\begin{array}{c}-0.79 \\
(0.14)^{* * *}\end{array}$ \\
\hline $\begin{array}{l}\text { Lesson Content (Reference } \\
\text { category- team) }\end{array}$ & & & $-0.80(0.37)$ & $-0.49(0.32)$ \\
\hline \multicolumn{5}{|l|}{$\begin{array}{c}\text { All variables } \\
\text { Random Part }\end{array}$} \\
\hline \multicolumn{5}{|l|}{ Class level variance } \\
\hline Pupil level variance & $11.89(0.83)^{* * *}$ & $11.36(0.79)^{* * *}$ & $\begin{array}{c}11.90 \\
(0.83)^{* * *}\end{array}$ & $\begin{array}{c}11.36(0.79)^{* *} \\
*\end{array}$ \\
\hline Deviance Test Model & 2391.64 & 2.361 .38 & 2389.36 & 2360.11 \\
\hline$\chi^{2}(\mathrm{df})$ & $12.72(1)^{* * *}$ & $2.32(1)$ & $6.88(1)^{* * *}$ & $1.94(1)$ \\
\hline
\end{tabular}

